\title{
Identification and Expression Patterns of Opsin Genes in a Forest Insect, Dendrolimus punctatus
}

\author{
Sufang Zhang, Xiangbo Kong, Fu Liu@ and Zhen Zhang * \\ Key Laboratory of Forest Protection of National Forestry and Grassland Administration, Research Institute of \\ Forest Ecology, Environment and Protection, Chinese Academy of Forestry, Beijing 100091, China; \\ zhangsf@caf.ac.cn (S.Z.); xbkong@sina.com (X.K.); liufu2006@163.com (F.L.) \\ * Correspondence: zhangzhen@caf.ac.cn; Tel.: +86-10-62889567; Fax: +86-10-62884972
}

Received: 30 December 2019; Accepted: 7 February 2020; Published: 11 February 2020

\begin{abstract}
Dendrolimus punctatus walker (Lepidoptera: Lasiocampidae) is the most serious coniferous forest defoliator in China. This species has long life history, and shows different activity rhythms and light response behaviors at larval and adult stages. Insect vision system play important roles for survival and reproduction, and disturbance of photoreception may help us to control this pest. However, we know little about the visual system of D. punctatus. As opsins are the most important genes determining photoreceptor sensitivity of insects, we identified opsins of D. punctatus and analyzed their expression patterns at different development stages in this study. Four opsin genes were identified based on our transcriptome data. Phylogenetic analysis showed that there are three classical ultraviolet (UV), blue, and long-wavelength (LW) light sensitive opsin genes, and another UV-like opsin as homolog of a circadian photoreceptor, Rh7, in Drosophila melanogaster and other insects. Expression analysis indicated that the UV and UV-like opsins expression levels only fluctuated slightly during whole life stages of D. punctatus, while Blue and LW opsins were up-regulated many times at adult stage. Interestingly, the ratio of UV-opsin was much higher in eggs and larvae stages, and lower in pupa and adult stages; reversely, LW-opsin showed extremely high relative ratio in pupa and adult stages. High expression level of LW opsin in the adult stage may correlate to the nocturnal lifestyles of this species at adult stage, and different ratios of UV and LW opsins in larval and adult stages may help to explain the different visual ecologies of these two development stages of D. punctatus. This work is the foundation for further research of opsin functions and vision mechanisms of $D$. punctatus.
\end{abstract}

Keywords: vision; long wave sensitive opsin; adult; expression level

\section{Introduction}

The interactions between pests and host plants rely on several sensory systems, such as olfaction, gustation, audition, and vision. Among these sensory systems, vision of insects plays important roles during foraging [1], host identification [2], mate choice [3], and predatory defense [4]. Some of these behaviors may be guided by a combination of sensory systems [5]. However, most researches about insect sensory systems were focused on olfaction [6] or gustation [7], and there have been much less focused on vision [8]. With the development of research techniques, the functions of vision in insect survival have attracted more attention recently [9].

Vision is underpinned by visual pigment molecules that contain a seven transmembrane opsin and a chromophore, usually 11-cis retinal. The amino acid sequence of the opsins and chromophores determine the spectral sensitivity of photoreceptors together [10-12]. Generally, opsins of insects can be divided into three types based on their pigment absorption spectral peaks, which are ultraviolet-sensitive (UV opsin, 325-400 nm), blue light-sensitive (Blue opsin, 400-500 nm), and long-wavelength-sensitive 
proteins (LW opsin, $>500 \mathrm{~nm}$ ) [13]. The UV, Blue, and LW opsins are three classic genes in insect visual system, and many insects such as hymenopterans contain all the three opsins, but less or more than three opsins appear in other insects due to gene duplication or losses $[14,15]$. For example, Apis mellifera contain three opsin genes corresponding to UV, Blue, and LW spectral peaks [16], six opsins were found in Drosophila [11], and six opsins were identified in Papilio glaucus [17]. The expression of opsin was also species specific, based on the evolution of insect visual systems shaped by the light environment [18-20].

In lepidopteran insects, the photoreception and compound eyes are highly developed, and adults of two main insects types in this order, butterflies and moths, have different responses to light rhythms. The butterflies are diurnal insects and some researchers have illustrated their adaption mechanisms to lights [21-23]. However, only very little work was related to the vision mechanisms of moths, which are most typical nocturnal insects [18,19]. Interestingly, the light sensitivity of moths is much higher than butterflies, because the moths have excellent low-light vision [24,25]. Moths are very sensitive to light traps, which are usually used in insect surveys and mass trapping of adults in pest management programs [26]. Determining the opsin copies and patterns of expressions in nocturnal moths may lead to more accurate regulation of their phototactic behaviors and assist in their management [27-30].

Dendrolimus punctatus walker (Lepidoptera: Lasiocampidae) is the most serious coniferous forest defoliator in south China, and this pest outbreak periodically [31]. Once outbreak, D. punctatus population density achieves a very high level, and the larvae feed on pine needles intensively, which may reduce the cone yield, affect tree growth, and even cause tree death [32]. Outbreaks of D. punctatus stimulated extensive insecticide application, and effected on biodiversity and natural enemies in the ecosystem. Thus, it is urgent to develop new methods to control this forest pest. The sensory systems connect insects with various information in the environment, and sensory block may be an efficient method to control D. punctatus. Until now, the olfactory sensory mechanisms of D. punctatus have been explored extensively [33-35]. However, little is known about another important sensory system, vision, of this pest. D. punctatus occurs one to four generations per year depending on the climate of occurring places. The eggs or adult stages maintain approximately one week, the pupae maintain approximately two weeks, and the larvae stage can fluctuate between one month and six months depending on different generations in a year [31]. It is worth mentioning that D. punctatus adults and larvae have different visual ecologies, because adults are nocturnal, and larvae are also active at daytime. However, the mechanisms that control their visual ecologies are unclear. As opsins are genes that underpin light response in insects, it is essential to identify and explore the expression patterns of opsins in this pest, and this may be the foundation for further research of vision mechanisms.

\section{Materials and Methods}

\subsection{Identification of Opsins}

The transcriptome data of D. punctatus at four development stages (including egg, larva, pupa, and adult) were same with our previous study [35], we also referenced the SRA database downloaded transcriptome data (accession SRP064724). To identify the opsins of D. punctatus, the contigs were analyzed with tBLASTx at NCBI, and the contigs hit with opsins of other species were further identified with their open reading frames (ORFs) by blast searches (http: //blast.ncbi.nlm.nih.gov/Blast.cgi). The identified opsins of D. punctatus was submitted to NCBI with accession number MN868672-MN868675.

\subsection{Sequencing Analysis and Phylogenetic Tree Construction}

D. punctatus opsins were aligned with DNAMAN (Version 8, LynnonBiosoft, QC, Canada). With TMHMM Server (Version 2.0, http://www.cbs.dtu.dk/services/TMHMM/), the transmembrane domains were identified. Protein sequences of opsins from D. punctatus and other insects were used to perform phylogenetic analysis. Both neighbor-joining (NJ) and maximum likelihood (ML) trees 
were constructed to confirm the results. The ML tree was constructed by MEGAX with 500 bootstrap replications, and Le and Gascuel, 2008 model [36] with frequencies and Gamma distributed sites $(\mathrm{LG}+\mathrm{F}+\mathrm{G})$ model of evolution was selected based on result of MEGA's model test. NJ tree was constructed using MEGAX with 10000 bootstrap replications and Poisson model + uniform rates. The tree was annotated in Adobe illustrator (Adobe Systems).

\subsection{Quantification of Gene Expression Levels with Real-time PCR}

We collected the pupae of D. punctatus in Quanzhou County, Guilin city, Guangxi Province, China, in May of 2018. The pupae were reared at $50 \pm 10 \%$ relative humidity and $26 \pm 2{ }^{\circ} \mathrm{C}$ with a photoperiod of $16 \mathrm{~h}$ light: $8 \mathrm{~h}$ dark. After emergence, some adults were immediately frozen in liquid nitrogen, and some of the adults were continuously reared for samples collection of various developmental stages. Eggs (approximately 2-3 d), larvae (a mix of all larval instars), and pupae (approximately $5 \mathrm{~d}$ ) samples were collected and frozen in liquid nitrogen. Samples of each developmental stage were collected from more than five insects in the morning of a day; and three biological replications for each development stage were prepared.

Then we extracted the total RNA from whole tissue of each sample with TRIzol, according to the manufacturer's instructions (Invitrogen, Carlsbad, CA, USA), and monitored the RNA degradation and contamination on $1.2 \%$ agarose gels. With $1 \mu \mathrm{g}$ of total RNA prepared above, cDNA templates were synthesized with M-MLV reverse transcriptase (Promega, USA), according to the manufacturer's instructions.

Primers that resulting 100-250 bp products were designed from the unigene sequences (Table 1). Normal PCR using qTaq DNA polymerase (TaKaRa, Dalian, Liaoning, China) and sequencing were performed to verify the correct products and no primer dimers. We used $2^{-\Delta \Delta} \mathrm{CT}$ method to measure the relative expression levels of opsin genes. As our pervious researches indicated that beta-actin is a reliable reference gene for real-time PCR in Dendrolimus insects [35], the expression level of opsin genes was normalized by beta-actin. The Real-time PCR were performed in $20 \mu \mathrm{L}$ reaction volume with $10 \mu \mathrm{L}$ of $2 \times$ SuperReal PreMix (Tiangen, Beijing, China) on an ABI7500 (USA), and the program was set as follow: $2 \mathrm{~min}$ at $95^{\circ} \mathrm{C}$, then 40 cycles of $20 \mathrm{~s}$ at $95^{\circ} \mathrm{C}, 20 \mathrm{~s}$ at $58{ }^{\circ} \mathrm{C}$, and $20 \mathrm{~s}$ at $72{ }^{\circ} \mathrm{C}$, at last $58^{\circ} \mathrm{C}$ to $95^{\circ} \mathrm{C}$ to perform melting curve analysis and evaluate the specificity of the real-time PCR products. Triplicates (technical replicates) were performed for each reaction, and three independent biological replicates were performed for each development stage.

Table 1. Primers used for real-time PCR.

\begin{tabular}{|c|c|}
\hline Purpose/Primer Name & Sequence $\left(5^{\prime}-3^{\prime}\right)$ \\
\hline DpunOpsinLW-5' & GCCTGCGGAACTGACTA \\
\hline DpunOpsinLW-3' & CGACAGCCTGAACAATAAA \\
\hline DpunOpsinBlue-5' & GCTGGAGATGCCTTTGC \\
\hline DpunOpsinBlue-3' & TGCTGGGAGGAGGGTAA \\
\hline DpunOpsinUV-5' & TGTTTCTTATTTGTGGCTTCC \\
\hline DpunOpsinUV-3' & TTGTCGTCGGGTTCGTC \\
\hline DpunOpsinUV-L-5' & TAGCGACTTTATCAGCA \\
\hline DpunOpsinUV-L-3' & CCATAGCCAATATCCAA \\
\hline Dpunbeta-Actin-5' & GCGATCTTACCGACTACCTCA \\
\hline Dpunbeta-Actin-3' & TCTGGGCAACGGAACCT \\
\hline
\end{tabular}

Gene expression level comparisons were performed by the SPSS statistical program (version 18.0; SPSS Inc., USA) with Analysis of variance (ANOVA) and Turkey's honestly significant difference (HSD) test. 


\section{Results}

\subsection{Opsin Identification and Sequence Analysis}

Based on the transcriptome data, we identified four opsin genes in D. punctatus, named as DpunOpsin blue, DpunOpsin UV, DpunOpsin UV-like, and DpunOpsin LW, respectively. These four opsins encoded 383, 378, 568, and 372 amino acid residue proteins, respectively. DpunOpsin UV like gene have a longer $5^{\prime}$ and $3^{\prime}$ end than other opsin genes, as shown in the aligned results, and all the four proteins have seven transmembrane domains (Figure 1).

\subsection{Phylogenetic Analysis of the Opsins}

Two phylogenetic comparisons with opsin protein sequences from D. punctatus and other species, including model insects such as Drosophila melanogaster, Apis mellifera, were constructed (Figure 2). Both NJ (Figure 2A) and ML (Figure 2B) trees showed that UV, Blue, and LW opsins from D. punctatus were clustered into three branches that similar to other insects, the UV like opsin gene of D. punctatus were separated to a single branch cluster with a circadian photoreceptor, Rh7, in Drosophila melanogaster and other insects.

\subsection{Expression Levels of the Opsins during Four Development Stages}

The expression levels of opsin genes relative to beta-actin during four development stages were different (Figure 3). Among the four opsins, DpunOpsin LW showed much higher expression level than other three genes, with about 20 times of DpunOpsin Blue, 30 times of DpunOpsin UV at adult stage. The DpunOpsin UV-like gene only showed very low expression level (Figure 3D). During different development stages, DpunOpsin LW and DpunOpsin Blue both up regulated their expression at adult stages greatly; but DpunOpsin UV and DpunOpsin UV-like opsin expression levels only fluctuated slightly from egg to adult. To further compare the ratios of various opsins at each developmental stage of D. punctatus, we illustrated the proportion of the four opsins gene expression levels at different developmental stages (Figure 3E). The results showed that ratio of DpunOpsin $U V$ was much higher in egg and larva stages, and lower in pupa and adult stages; reversely, DpunOpsin LW showed extremely high relative ratios in pupa and adult stages. These may help to explain the different visual ecologies of larval and adult stages of D. punctatus. 


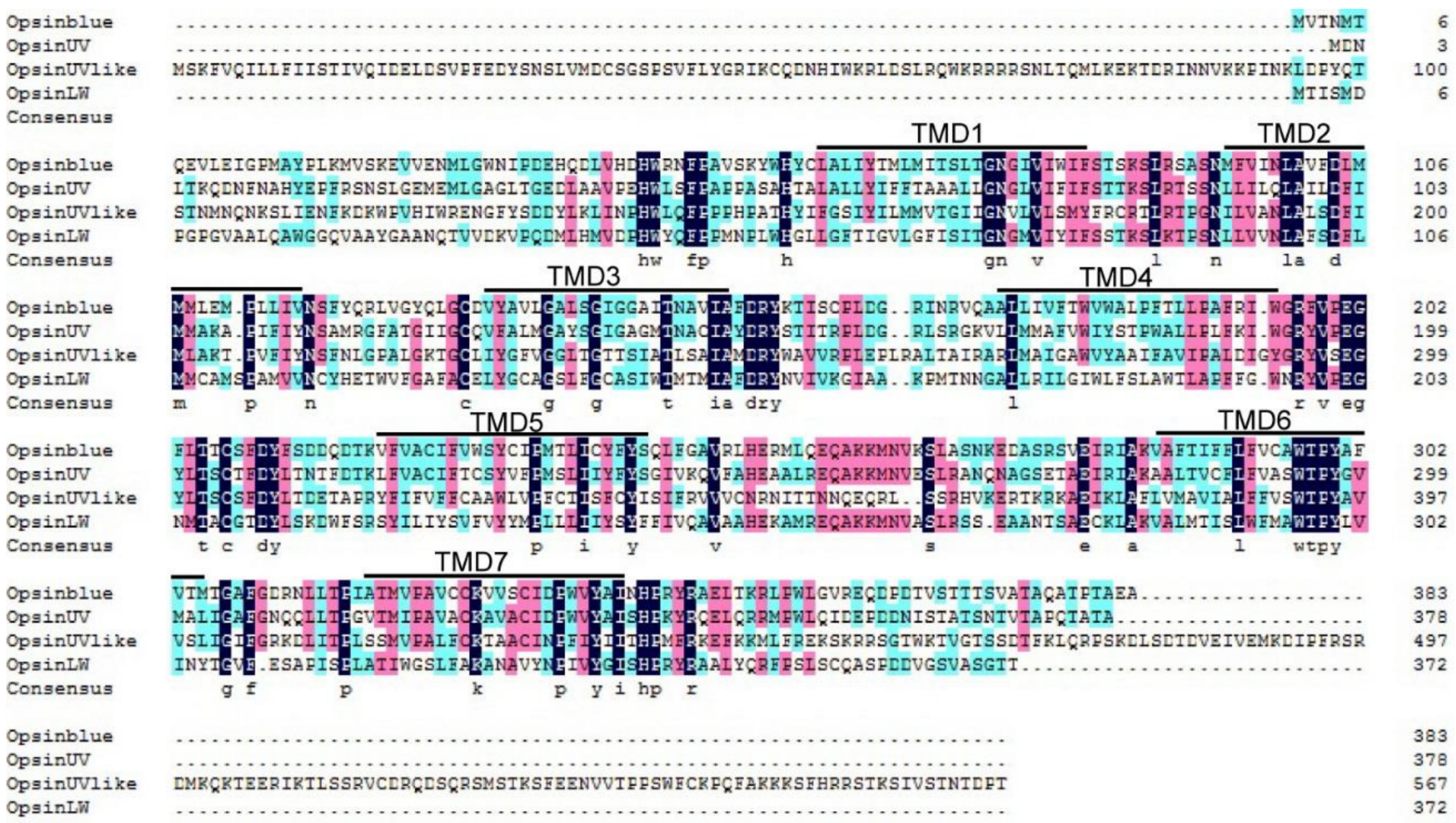

OpsinL

Figure 1. Sequence alignment of four opsins from Dendrolimus punctatus. The seven transmembrane domains are marked above the alignments as TMD1-7. 


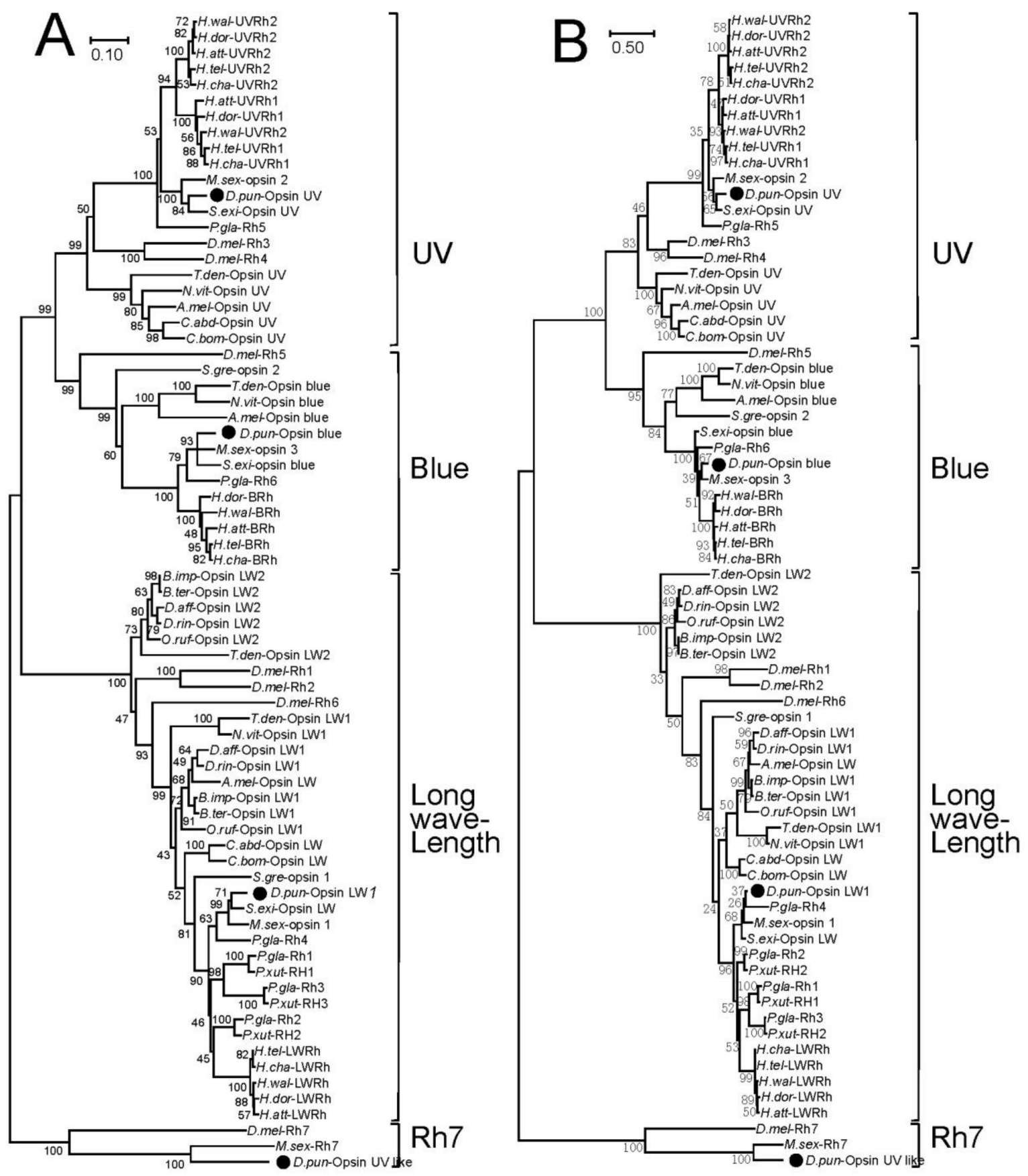

Figure 2. Neighbor-joining (NJ) and maximum likelihood (ML) trees based on protein sequences of opsin from Dendrolimus punctatus and other insects. Opsins from Dendrolimus punctatus (D.pun); Drosophila melanogaster (D.mel); Apis mellifera (A.mel); Trichogramma dendrolimi (T.den); Camponotus abdominalis (C.abd); Cataglyphis bombycinus (C.bom); Manduca sexta (M.sex); Papilio glaucus (P.gla); P. xuthus (P.xut); Schistocerca gregaria (S.gre); Bombus impatiens (B.imp), B. terrestris (B.ter); Diadasia afflicta (D.aff); D. rinconis (D.rin); Osmia rufa (O.ruf); Heliconius wallacei (H.wal); Heliconius telesiphe (H.tel); Heliconius doris (H.dor); Heliconius charithonia (H.cha); Heliconius atthis (H.att); Spodoptera exigua (S.exi) (A) NJ tree constructed using MEGAX with 10000 bootstrap replications and Poisson model+uniform rates. (B) ML tree constructed by MEGAX with 500 bootstrap replications, and Le and Gascuel, 2008 model with frequencies and Gamma distributed sites $(\mathrm{LG}+\mathrm{F}+\mathrm{G})$ model of evolution. The bar indicates phylogenetic distance, and the black points refer to the opsins of Dendrolimus punctatus. 

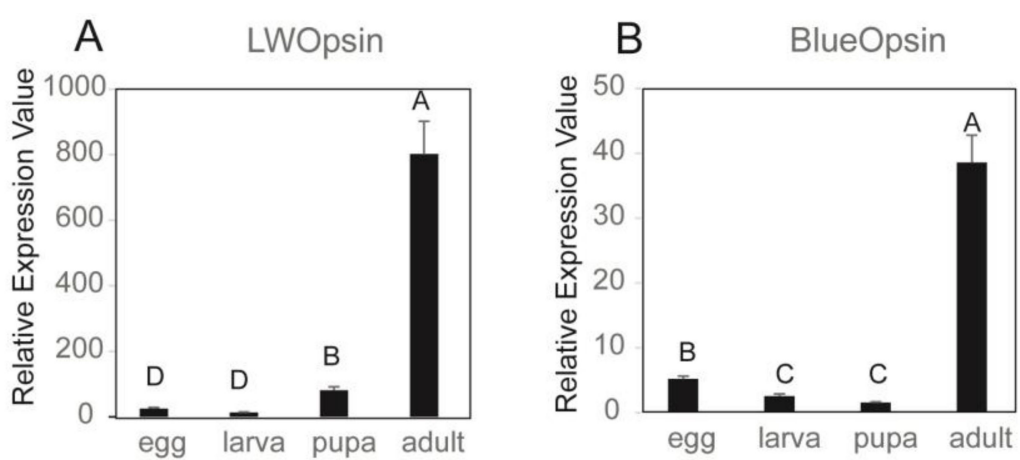

C

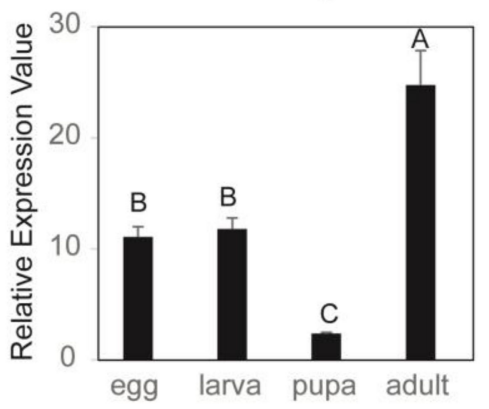

D UVlikeOpsin

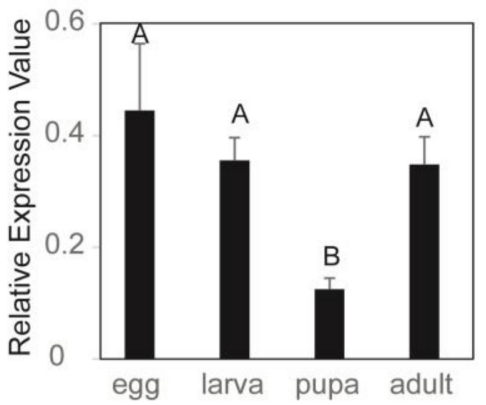

$E$

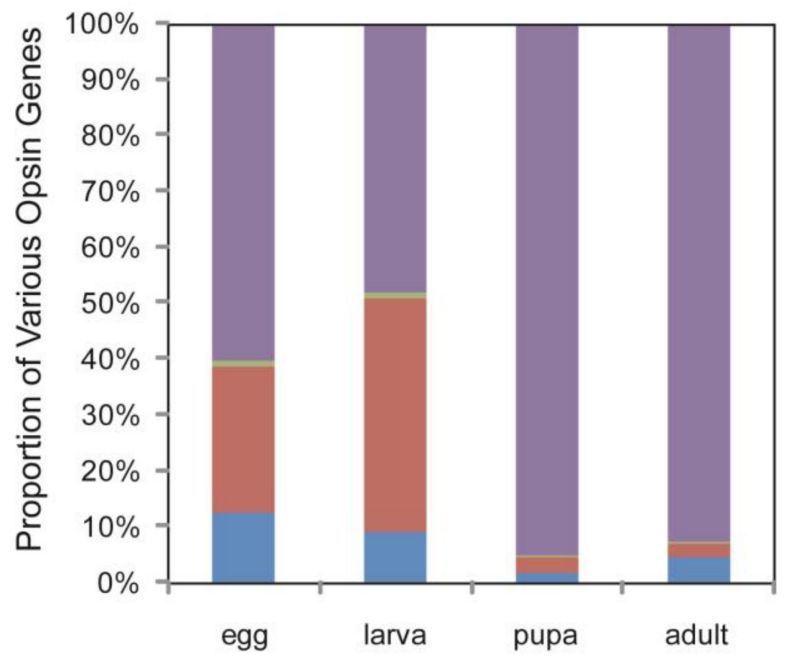

Figure 3. Development stages-dependent expression levels and ratios of the four opsin genes in D. punctatus. (A) expression levels of DpunOpsin LW; (B) expression levels of DpunOpsin blue; (C) expression levels of DpunOpsin UV; (D) expression levels of DpunOpsin UV=like; (E) ratios of various opsins at each developmental stage. Real-time PCR was performed using various tissue samples of Dendrolimus punctatus, and the expression values were normalized to that of $\beta$-actin in A-D. Three replications were performed, and the expression data were shown as mean \pm SE in A-D and mean value in E. The letters above each bar of A-D indicate significant differences according to a Tukey' honestly significant difference (HSD) test $(p<0.05)$.

\section{Discussion}

As a serious defoliator of pine forests, vision system disturbance, such as more efficient light trapping, or genetic manipulation of the critical opsin genes of D. punctatus, maybe efficient method to control their population and damage. In this work, we identified and analyzed the important vision 
genes, opsins, in D. punctatus. The results are foundation for further gene function studies and pest photoreception disturbance.

Based on previous studies, there are normally three types of opsins in lepidopteran insects, including butterflies and moths $[13,19,30,37]$. All the three opsin types were identified in D. punctatus, which were UV, B, and LW opsins. Additionally, another UV-like opsin was identified. The phylogenetic analysis showed that this UV-like genes was relatively far from the main UV cluster, and it was separated to a single branch cluster with a circadian photoreceptor, Rh7, in Drosophila melanogaster and other insects. The expression level of this UV-like gene was very low compared to other opsins, which was according to that of Rh7 in Drosophila [38,39].

Expression analysis of the four opsins in D. punctatus showed that their ratios were different at four development stages. Ratios of UV-opsin were much higher in egg and larva stages, and lower in pupa and adult stages. Reversely, LW-opsin showed extremely high relative ratios in pupa and adult stages (Figure 3E). These may explain the different visual ecologies of larval and adult stages of D. punctatus. UV opsin showed only slight up regulation from larval to adult stages, but the eye size increased significantly relative to body size in adult stages, so we can still expect a larger relative contribution of UV to the visual system in larvae vs adults. LW opsin is the main one expressed in adults, which is according to the results of Spodoptera exigua [30] and Manduca Sexta [40]. This situation may correlate with the nocturnal lifestyles of adult moths, as high LW expression level may help the insect to adapt the low light environment during the night $[24,25]$.

A recent study in S. exigua showed that LW opsin knockdown led to reduced green light phototactic efficiency in adults [30], confirming that the high expression level of LW opsin gene in adults contribute to phototaxy of moths. However, studies on opsin gene functions of moth larvae are rare and differences in opsin expression patterns between different life stages were not previously known. Thus, the molecular bases of different visual ecologies of larva and adult stages were unclear. Our study gives evidence that the expression ratios of different opsins in larva and adult D. punctatus are different, but further in vivo function studies are needed to explore the mechanisms of different visual ecologies in different development stages.

\section{Conclusions}

Four opsin genes of D. punctatus were identified based on our transcriptome data of different development stages. Phylogenetic analysis showed that there were three classical opsin genes, which were sensitive to UV, Blue and LW light, and another circadian photoreceptor. Gene expression analysis showed that ratio of DpunOpsin $U V$ was much higher in egg and larva stages, and lower in pupa and adult stages; reversely, DpunOpsin LW showed extremely high relative ratios in pupa and adult stages. The different expression ratios of DpunOpsin $U V$ and DpunOpsin LW in different development stages of $D$. punctatus may be adapted to maximize light sensitivity according to the visual ecologies of larval and adult stages.

Author Contributions: S.Z. designed the experiments and performed the bioinformatic analysis, as well as drafted the manuscript. X.K. and F.L. collected the insect. Z.Z. designed and modified the manuscript. All authors have read and agreed to the published version of the manuscript.

Funding: This work was supported by the Fundamental Research Funds of CAF (CAFYBB2017QB003), The National Key Research and Development Program of China (2017YFD0600102 and2018YFC1200400), and The National Nature Science Foundation of China (31670657).

Acknowledgments: We thank Zhongwu Yang for his help in insect collection.

Conflicts of Interest: We declare that the research was conducted in the absence of any commercial or financial relationships that could be construed as a potential conflict of interest. 


\section{References}

1. Weiss, M.R. Vision and learning in some neglected pollinators: Beetles, flies, moths, and butterflies. In Cognitive Ecology of Pollination: Animal Behaviour and Floral Evolution; Thomson, J.D., Chittka, L., Eds.; Cambridge University Press: Cambridge, UK, 2001; pp. 171-190.

2. Kelber, A. Ovipositing butterflies use a red receptor to see green. J. Exp. Biol. 1999, 202, 2619. [PubMed]

3. Jiggins, C.D.; Naisbit, R.E.; Coe, R.L.; Mallet, J. Reproductive isolation caused by colour pattern mimicry. Nature 2001, 411, 302-305. [CrossRef] [PubMed]

4. Endler, J.A.; Mappes, J. Predator mixes and the conspicuousness of aposematic signals. Am. Nat. 2004, 163, 532-547. [CrossRef] [PubMed]

5. Tang, Y.C.; Zhou, C.-L.; Chen, X.-M.; Zheng, H. Visual and olfactory responses of seven butterfly species during foraging. J. Insect Behav. 2013, 26, 387-401. [CrossRef]

6. Su, C.Y.; Menuz, K.; Carlson, J.R. Olfactory perception: Receptors, cells, and circuits. Cell 2009, 139, 45-59. [CrossRef] [PubMed]

7. Agnihotri, A.R.; Roy, A.A.; Joshi, R.S. Gustatory receptors in Lepidoptera: Chemosensation and beyond. Insect Mol. Biol. 2016, 25, 519-529. [CrossRef]

8. Schoonhoven, L.M.; Van Loon, B.; Van Loon, J.J.; Dicke, M. Insect-Plant Biology; Oxford University Press on Demand: Oxford, UK, 2005.

9. Reeves, J.L. Vision should not be overlooked as an important sensory modality for finding host plants. Environ. Entomol. 2011, 40, 855-863. [CrossRef]

10. Shichida, Y.; Imai, H. Visual pigment: G-protein-coupled receptor for light signals. Cell. Mol. Life Sci. CMLS 1998, 54, 1299-1315. [CrossRef]

11. Gartner, W.; Towner, P. Invertebrate visual pigments. Photochem. Photobiol. 1995, 62, 1-16. [CrossRef]

12. Terakita, A. The opsins. Genome Biol. 2005, 6, 213. [CrossRef]

13. Briscoe, A. The evolution of color vision in insects. Annu. Rev. Entomol. 2001, 46, 471. [CrossRef]

14. Pohl, N.; Sison-Mangus, M.P.; Yee, E.N.; Liswi, S.W.; Briscoe, A.D. Impact of duplicate gene copies on phylogenetic analysis and divergence time estimates in butterflies. BMC Evol. Biol. 2009, 9, 99. [CrossRef] [PubMed]

15. Wakakuwa, M.; Kurasawa, M.; Giurfa, M.; Arikawa, K. Spectral heterogeneity of honeybee ommatidia. Naturwissenschaften 2005, 92, 464-467. [CrossRef] [PubMed]

16. Menzel, R.; Backhaus, W. Color Vision Honey Bees: Phenomena and Physiological Mechanisms; Springer Berlin Heidelberg: Heidelberg, Germany, 1989.

17. Briscoe, A.D. Six opsins from the butterfly Papilio Glaucus: Molecular phylogenetic evidence for paralogous origins of red-sensitive visual pigments in insects. J. Mol. Evol. 2000, 51, 110-121. [CrossRef] [PubMed]

18. Yan, S.; Zhu, J.; Zhu, W.; Zhang, X.; Li, Z.; Liu, X.; Zhang, Q. The expression of three opsin genes from the compound eye of Helicoverpa armigera (lepidoptera: Noctuidae) is regulated by a circadian clock, light conditions and nutritional status. PLoS ONE 2014, 9, e111683. [CrossRef]

19. Xu, P.; Lu, B.; Xiao, H.; Fu, X.; Murphy, R.W.; Wu, K. The evolution and expression of the moth visual opsin family. PLoS ONE 2013, 8, e78140. [CrossRef]

20. Hartman, S.J.; Menon, I.; Haug-Collet, K.; Colley, N.J. Expression of rhodopsin and arrestin during the light-dark cycle in Drosophila. Mol. Vis. 2001, 7, 95-100.

21. Vanhoutte, K.J.A.; Eggen, B.J.L.; Janssen, J.J.M.; Stavenga, D.G. Opsin cDNA sequences of a UV and green rhodopsin of the satyrine butterfly Bicyclus anynana. Insect Biochem. Mol. Biol. 2002, 32, 1383-1390. [CrossRef]

22. Stavenga, D.G.; Arikawa, K. Evolution of color and vision of butterflies. Arthropod Struct. Dev. 2006, 35, 307-318. [CrossRef]

23. Frentiu, F.D.; Bernard, G.D.; Cuevas, C.I.; Sison-Mangus, M.P.; Prudic, K.L.; Briscoe, A.D. Adaptive evolution of color vision as seen through the eyes of butterflies. Proc. Natl. Acad. Sci. USA 2007, 104, 8634-8640. [CrossRef]

24. Warrant, E.; Dacke, M. Vision and visual navigation in nocturnal insects. Annu. Rev. Entomol. 2011, 56, 239-254. [CrossRef]

25. Yan, S.; Meng, Q.; Zhao, S.; Lu, W.; Zhu, J.; Hui, L. Compound eyes vision of nocturnal moth and its light trap response. China Plant Prot. 2017, 37, 30-35. 
26. Oh, M.S.; Lee, C.H.; Lee, S.G.; Lee, H.S.; Oh, M.S.; Lee, C.H.; Lee, S.G.; Lee, H.S. Evaluation of high power light emitting diodes (hpleds) as potential attractants for adult Spodoptera exigua (Hübner) (Lepidoptera: Noctuidae). Environ. Sci. 2011, 54, 416-422. [CrossRef]

27. Ballinger, D.G.; Benzer, S. Photophobe (ppb), a Drosophila mutant with a reversed sign of phototaxis; The mutation shows an allele-specific interaction with sevenless. Proc. Natl. Acad. Sci. USA 1988, 85, 3960-3964. [CrossRef] [PubMed]

28. Inada, K.; Horie, T.; Kusakabe, T.; Tsuda, M. Targeted knockdown of an opsin gene inhibits the swimming behaviour photoresponse of ascidian larvae. Neurosci. Lett. 2003, 347, 167-170. [CrossRef]

29. Gühmann, M.; Jia, H.; Randel, N.; Verasztó, C.; Bezares-Calderón, L.A.; Michiels, N.K.; Yokoyama, S.; Jékely, G. Spectral tuning of phototaxis by a go-opsin in the rhabdomeric eyes of Platynereis. Curr. Biol. 2015, 25, 2265-2271. [CrossRef] [PubMed]

30. Liu, Y.-J.; Yan, S.; Shen, Z.-J.; Li, Z.; Zhang, X.-F.; Liu, X.-M.; Zhang, Q.-W.; Liu, X.-X. The expression of three opsin genes and phototactic behavior of Spodoptera exigua (lepidoptera: Noctuidae): Evidence for visual function of opsin in phototaxis. Insect Biochem. Mol. Biol. 2018, 96, 27-35. [CrossRef]

31. Xiao, G. Forest Insects of China, 2nd ed.; China Forestry Publishing House: Beijing, China, 1992; pp. 961-963.

32. Zhao, C.H.; Li, Q.; Guo, X.Y.; Wang, X.Y. New components of sex pheromone in the pine caterpillar moth, Dendrolimus punctatus: Identification of chemical structures and field tests. Acta Entomol. Sin. 1993, 36, 247-350.

33. Zhang, S.-F.; Zhang, Z.; Kong, X.-B.; Wang, H.-B. Molecular characterization and phylogenetic analysis of three odorant binding protein gene transcripts in Dendrolimus species (lepidoptera: Lasiocampidae). Insect Sci. 2014, 21, 597-608. [CrossRef]

34. Zhang, S.-F.; Zhang, Z.; Kong, X.-B.; Wang, H.-B.; Liu, F. Dynamic changes in chemosensory gene expression during the Dendrolimus punctatus mating process. Front. Physiol. 2018, 8, 1127. [CrossRef]

35. Zhang, S.-F.; Liu, H.-H.; Kong, X.-B.; Wang, H.-B.; Liu, F.; Zhang, Z. Identification and expression profiling of chemosensory genes in Dendrolimus punctatus walker. Front. Physiol. 2017, 8, 471. [CrossRef] [PubMed]

36. Le, S.Q.; Olivier, G. An Improved General Amino Acid Replacement Matrix. Mol. Biol. Evol. 2008, 25, 1307-1320. [CrossRef] [PubMed]

37. Awata, H.; Wakakuwa, M.; Arikawa, K. Evolution of color vision in pierid butterflies: Blue opsin duplication, ommatidial heterogeneity and eye regionalization in Colias erate. J. Comp. Physiol. A 2009, 195, 401-408. [CrossRef] [PubMed]

38. Ni, J.D.; Baik, L.S.; Holmes, T.C.; Montell, C. A rhodopsin in the brain functions in circadian photoentrainment in Drosophila. Nature 2017, 545, 340-344. [CrossRef]

39. Sakai, K.; Tsutsui, K.; Yamashita, T.; Iwabe, N.; Takahashi, K.; Wada, A.; Shichida, Y. Drosophila melanogaster rhodopsin Rh7 is a UV-to-visible light sensor with an extraordinarily broad absorption spectrum. Sci. Rep. 2017, 7, 7349. [CrossRef]

40. White, R.H.; Xu, H.; Münch, T.A.; Bennett, R.R.; Grable, E.A. The retina of Manduca sexta: Rhodopsin expression, the mosaic of green-, blue- and uv-sensitive photoreceptors, and regional specialization. J. Exp. Biol. 2003, 206, 3337-3348. [CrossRef] [PubMed]

(C) 2020 by the authors. Licensee MDPI, Basel, Switzerland. This article is an open access article distributed under the terms and conditions of the Creative Commons Attribution (CC BY) license (http://creativecommons.org/licenses/by/4.0/). 